Article

\title{
Benchmarking the Retrieval of Biomass in Boreal Forests Using P-Band SAR Backscatter with Multi-Temporal C- and L-Band Observations
}

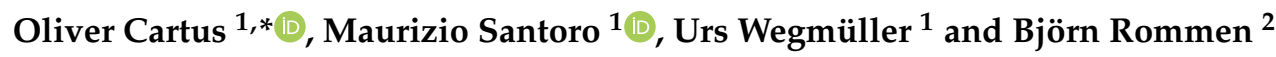 \\ 1 Gamma Remote Sensing, Worbstrasse 225, 3073 Gümligen, Switzerland \\ 2 European Space Agency-ESTEC, 2201 Noordwijk, The Netherlands \\ * Correspondence: cartus@gamma-rs.ch; Tel.: +41-31-951-7005
}

Received: 30 May 2019; Accepted: 12 July 2019; Published: 17 July 2019

check for updates

\begin{abstract}
The planned launch of a spaceborne P-band radar mission and the availability of $\mathrm{C}$ - and L-band data from several spaceborne missions suggest investigating the complementarity of C-, L-, and P-band backscatter with respect to the retrieval of forest above-ground biomass. Existing studies on the retrieval of biomass with multi-frequency backscatter relied on single observations of the backscatter and were thus not able to demonstrate the potential of multi-temporal C-and L-band data that are now available from spaceborne missions. Based on spaceborne C- and L-band and airborne P-band images acquired over a forest site in southern Sweden, we investigated whether Cand L-band backscatter may complement retrievals of above-ground biomass from P-band. To this end, a retrieval framework was adopted that utilizes a semi-empirical model for C- and L-bands and an empirical parametric model for P-band. Estimates of above-ground biomass were validated with the aid of $20 \mathrm{~m}$-diameter plots and a LiDAR-derived biomass map with $100 \mathrm{~m} \times 100 \mathrm{~m}$ pixel size. The highest retrieval accuracy when not combining frequencies was obtained for P-band with a relative root mean square error (RMSE) of 30\% at the hectare scale. The retrieval with multi-temporal L- and C-bands produced errors of the order of $40 \%$ and $50 \%$, respectively. The P-band retrieval could be improved for $4 \%$ when using P-, L-, and C-bands jointly. The combination of C- and L-bands allowed for retrieval accuracies close to those achieved with P-band. A crucial requirement for achieving an error of 30\% with C- and L-bands was the use of multi-temporal observations, which was highlighted by the fact that the retrieval with the best individual L-band image was associated with an error of $61 \%$. The results of this study reconfirmed that P-band is the most suited frequency for the retrieval of above-ground biomass of boreal forests based on backscatter, but also highlight the potential of multi-temporal C- and L-band imagery for mapping above-ground biomass, for instance in areas where the planned ESA BIOMASS P-band mission will not be allowed to acquire data.
\end{abstract}

Keywords: above-ground biomass; SAR; multi-frequency; multi-temporal; hemi-boreal forest

\section{Introduction}

Synthetic aperture radar (SAR) backscatter represents one of the Earth observation data types that have shown potential for mapping forest above-ground biomass [1-3], i.e., the dry weight of trees per unit area excluding belowground tree components. Although other data types and observables are expected to allow for higher retrieval accuracies, in particular in high biomass forests, e.g., radar polarimetry [4] or tomography [5], the use of backscatter observations is still of interest. SAR images have been acquired globally for more than two decades by spaceborne C- and L-band missions and will be acquired in the foreseeable future by several planned missions. In particular, the time series of C- and L-band observations will complement data acquired by the BIOMASS P-band mission in few years' time. 
The correlation of radar backscatter measurements with above-ground biomass is a consequence of the inherent correlations between the "sensed" aspects of forest structure and above-ground biomass. Physical scattering models generally agree in that the penetration of the signal into the canopy and the scattering from larger tree components increases with increasing wavelength. The relative contribution of scattering arising from different tree components also depends on polarization, incidence angle, environmental conditions (frozen/unfrozen conditions, plant water status), and tree architecture [6-9]. While at higher frequencies (X/C-band), backscatter is expected to originate primarily from smaller tree components (i.e., needles, foliage, small branches), scattering from primary branches and stems becomes relevant, if not dominant, at lower frequencies, e.g., P-band at $\mathrm{HH}$ polarization $[6,7,10]$. The modeling therefore suggests that different radar frequencies and polarizations should best be suited for estimating the biomass contained in different tree components and that the retrieval of above-ground biomass should benefit from the availability of multi-frequency observations.

The inability of any single radar frequency to sense forest structure in its entirety has motivated the exploration of multi-frequency approaches for estimating above-ground biomass [11-21]. While the results of these studies tend to confirm that the use of multi-frequency radar data allows for improved retrieval accuracies, only few studies investigated if the benefit of using multi-frequency data actually lies in the fact that each frequency maximizes the sensitivity to the biomass contained in specific tree components $[12,14,15]$. Based on airborne multi-frequency radar data $(\mathrm{C}, \mathrm{L}, \mathrm{P})$, Kasischke et al. [14] showed for pine forest in the southeastern United states that the biomass in branches could be predicted with the highest accuracy and that total above-ground biomass was best estimated by applying allometric relationships, converting radar-derived branch to total above-ground biomass. Compared to a direct retrieval of above-ground biomass, for which the root mean square error (RMSE) with respect to the mean biomass was $35.8 \%$, the retrieval of above-ground biomass via radar-derived estimates of branch biomass and allometric models resulted in an error of $22.5 \%$. Dobson et al. [12] proposed a retrieval approach in which above-ground biomass is estimated via independent estimates of stem and crown biomass from polarimetric C- and L-band. For a forest site in northern Michigan, Dobson et al. reported that stem biomass could be estimated with an RMSE of $11 \mathrm{t} / \mathrm{ha}$, and branch biomass with an RMSE of $5 \mathrm{t} / \mathrm{ha}$. The sum of independent stem and branch biomass estimates allowed for estimating above-ground biomass with an RMSE of $14 \mathrm{t} / \mathrm{ha}$. A comparison of the performance of the proposed retrieval approach with that achieved when estimating above-ground biomass directly from the radar data was not presented. Such a comparison was presented in [19] for pine forests in the southeastern United States. Harrell et al. [19] compared the performance of the approaches suggested in $[12,14]$ with the performance of a retrieval in which multi-frequency backscatter is directly related to above-ground biomass. Based on SIR-C C- and L-band data, they showed that the three different approaches produced above-ground biomass estimates with comparable accuracy (RMSE of $81 \mathrm{t} / \mathrm{ha}$ for the direct retrieval; 85 and $87 \mathrm{t} / \mathrm{ha}$ for the methods proposed in [12,14], respectively). Airborne C-, L-, and P-band observations were used for estimating the biomass in stems and canopy of conifers in Yellowstone National Park in [15]. Saatchi et al. [15] reported that the retrieval of canopy biomass was possible with similar accuracy when using L- or P-bands ( $R^{2}$ of 0.55$)$; a combined use of L-HV and P-HV backscatter yielded the highest accuracy $\left(R^{2}\right.$ of 0.73$)$. In the case of stem biomass, the retrieval performance was higher at P-band $\left(R^{2}\right.$ of 0.81$)$ than at L-band $\left(R^{2}\right.$ of 0.57$)$ and did not improve when combining frequencies.

The results of existing studies on the retrieval of above-ground biomass and biomass components were overall inconclusive with respect to the assumption that multi-frequency radar allows for improved biomass estimates because each frequency/polarization maximizes the sensitivity to a particular biomass component. Reasons for this may be associated with (i) the high inherent correlations between total above-ground biomass and the biomass contained in different tree components hindering the identification of causative relationships [22], or (ii) the effect of varying environmental imaging conditions that potentially introduce backscatter variations of similar magnitude as the backscatter changes associated with changing biomass. Most of the existing studies on the relationship of 
multi-frequency backscatter and component biomass relied on mono-temporal radar datasets and were thus not able to account for differences in the imaging conditions. However, it was demonstrated that C-band backscatter presents temporally and spatially variable relationships with biomass and low temporal consistency depending on the soil and vegetation conditions (moisture, snow cover, freeze/thaw) [23-25]. Although still relevant, environmental effects on the backscatter to biomass relationship at lower frequencies (L/P-band) tend to be less pronounced [25-33].

Thanks to the availability of multiple images acquired during the year 2010 by spaceborne ERS-2 and Radarsat-2 sensors (C-band), the ALOS PALSAR (L-band) sensor, and the airborne SETHI instrument (P-band) over the forest site of Remningstorp in Sweden [34,35], the scope of our study was to appraise the benefit of short- and long-wavelength observations of the SAR backscatter to estimate forest above-ground biomass and biomass components so to advance the partial knowledge gathered in previous work on such combination of frequencies. More specifically, the objectives of this study were to assess:

- differences in the performance of the retrieval of above-ground, stem, and branch biomass between C-, L-, and P-band,

- $\quad$ whether the joint use of multi-temporal C-, L-, and P-bands allows for improving the retrieval of above-ground biomass compared to using data acquired at a single frequency, in particular at P-band,

- $\quad$ and whether retrieval approaches in which above-ground biomass is estimated via independent radar-derived estimates of stem and branch biomass allow for improving the retrieval.

\section{Study Area and Reference Data}

The study area coincided with the Remningstorp forest site located in southern Sweden (Figure 1, left). The test site comprises about 1200 ha of managed forest dominated by Norway spruce, Scots pine, and birch. Pines grow on sandy soils; spruce and birch on till. The topography is generally flat with only minor ground elevation variations across the test site.
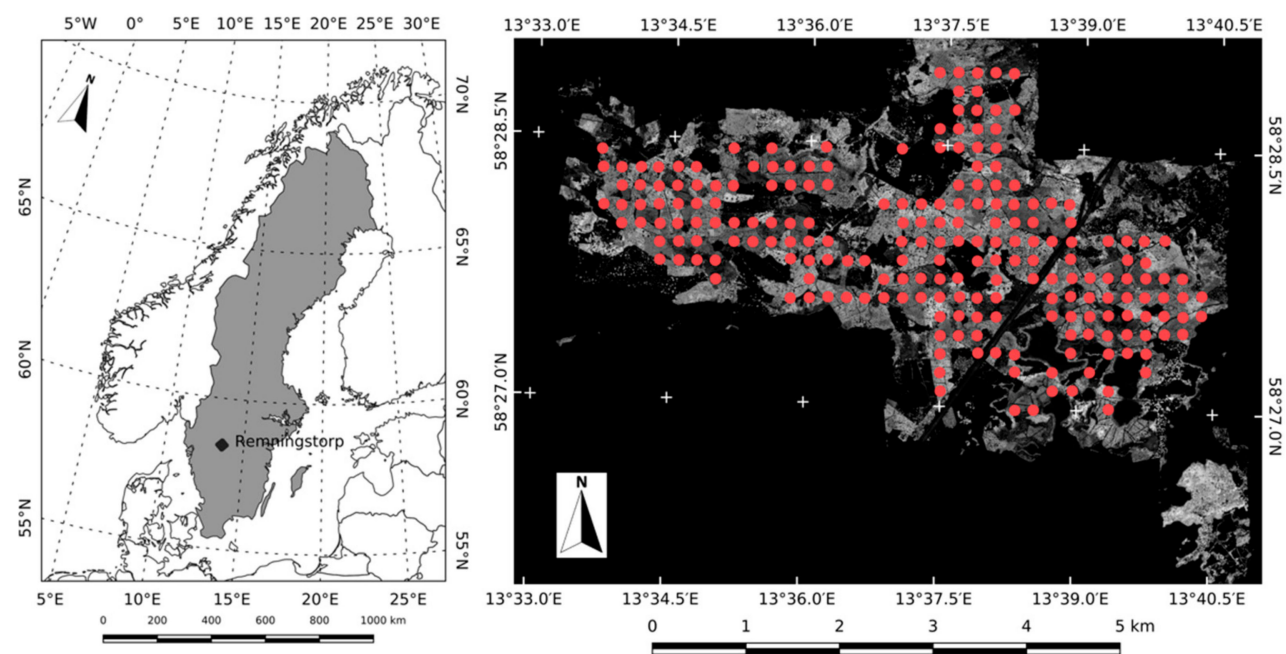

Figure 1. Location of the Remningstorp test site in Sweden (left). Circular plots established in Remningstorp in 2010 with a LiDAR canopy surface model in the background (right) [35].

\subsection{In Situ Data}

The in situ data set consisted of 214 circular forest field inventory plots surveyed in the frame of the BIOSAR campaigns [34,35] in September and October 2010 (Figure 1, right). The diameter of each inventory plot was $20 \mathrm{~m}$. In each plot, the inventory measured the diameter at breast height (dbh), tree height (for a sub-sample of trees), species, and age. Estimates of biomass were obtained with 
allometric equations developed for spruce, pine, and birch, which considered dbh, age, site index, and the last five years' radial growth [36]. The equations are provided in the Supplementary Materials. The set of equations was used to estimate the biomass contained in stems (incl. bark) and branches (incl. leaves/needles), separately. The equations for birch were applied for all broadleaved species in the test area. The error of the biomass estimates at tree level was reported as high as 30\%, depending on the species [30], but was expected to decrease to a level of a few percent when averaging over all trees measured within a plot. The plots were labelled as spruce, pine, or deciduous forest, respectively, when the stem volume of a species exceeded the volume of all other species in the plot. 130 plots were labelled as spruce, 43 as pine, and 41 as deciduous. Except for two plots, the assigned species contained more than $50 \%$ of the total stem volume. On average, the assigned species contained about $90 \%$ of the stem volume in a plot.

To identify major structural differences in the forests at the test site, Figure 2 illustrates the total aboveground biomass and the biomass of stems and branches with respect to the age of spruce, pine, and deciduous forests. Deciduous species, which in natural boreal forest succession are generally replaced by conifers within few decades after disturbance, were characterized by an above-ground biomass below $150 \mathrm{t} / \mathrm{ha}$. Stem and branch biomass of deciduous forests hardly exceeded $50 \mathrm{t} / \mathrm{ha}$. The highest above-ground biomass of $\sim 300 \mathrm{t} / \mathrm{ha}$ was reached by spruce after about 60 years of growth. In terms of stem and branch biomass, the highest values of 250 and 50-60 t/ha, respectively, were as well reached by spruce only. Pine, for which the majority of plots reported an age of more than 50 years, reached a maximum above-ground biomass of $150 \mathrm{t} / \mathrm{ha}$. The age differences between spruce and pine imply that at comparable levels of above-ground biomass, pine and spruce plots presented clear structural differences. Since the proportion of above-ground biomass contained in branches decreased with increasing age (Figure 2, bottom left), pine stands contained a higher proportion of biomass in stems than spruce stands with similar above-ground biomass.
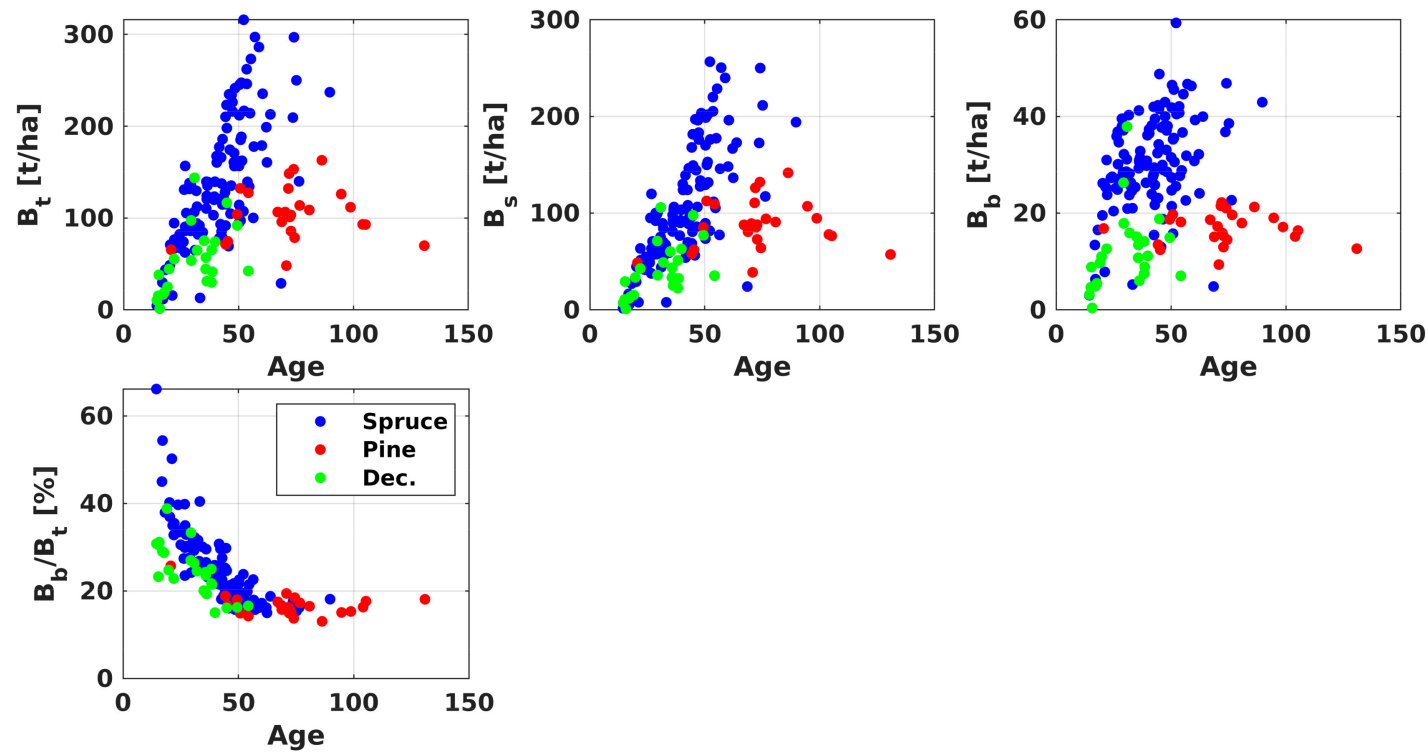

Figure 2. Above-ground ( $B_{t}$, top left), stem ( $B_{s}$, top center), and branch biomass $\left(B_{b}\right.$, top right) as functions of forest age. Proportion of above-ground biomass in branches as a function of age (bottom left).

The structural differences between spruce, pine, and deciduous forests implied different allometric relationships between branch and aboveground biomass (Figure 3, right). While the Pearson correlation coefficients between branch biomass and above-ground biomass were comparable ( 0.9 for spruce, 0.89 for pine, 0.86 for deciduous forests), the allometric relationship in the case of spruce differed from the relationships observed for pine and deciduous forests in that at comparable branch biomass levels the 
corresponding above-ground biomass was lower for spruce $(\sim 50 \%)$. The differences in the allometric relationships between stem and above-ground biomass were less pronounced (Figure 3, left). The Pearson correlation coefficients were close to one for all species. Due to differences in branch biomass, the above-ground biomass of spruce was on average about $10 \mathrm{t} /$ ha higher than for pine and deciduous forests in stem biomass ranges above $\sim 40 \mathrm{t} / \mathrm{ha}$.
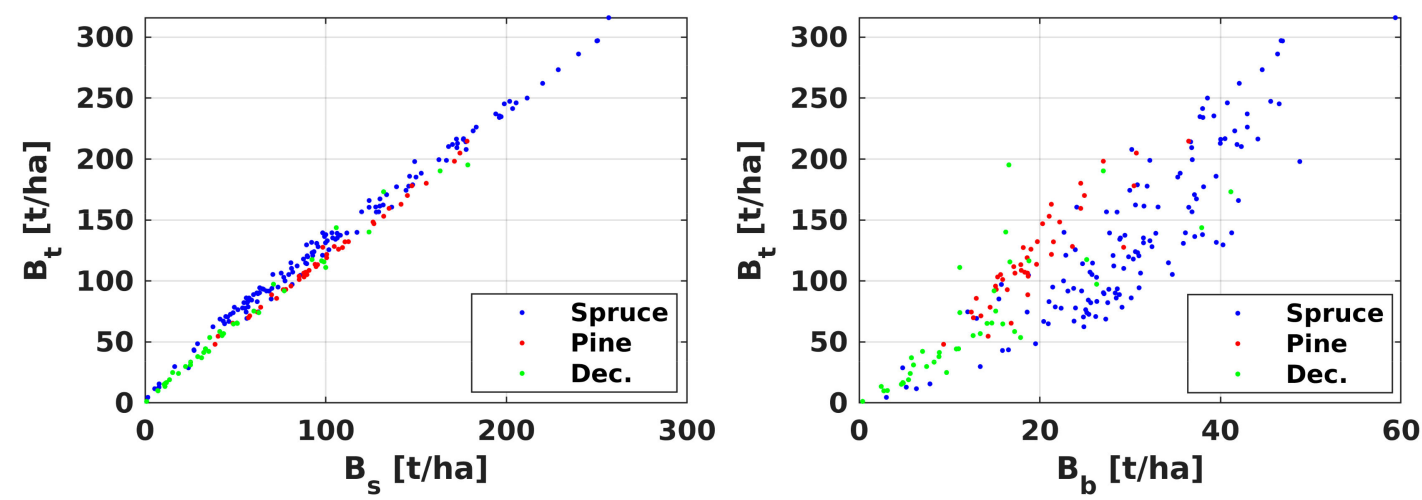

Figure 3. Relationship between stem and above-ground biomass (left) and branch and above-ground biomass (right) for spruce, pine, and deciduous forests in Remningstorp.

\subsection{LiDAR Data}

An airborne LiDAR campaign was carried out in August 2010 using a helicopter-mounted laser scanner [35]. The campaign covered an area of $22 \mathrm{~km}^{2}$. The average density of LiDAR returns was $69 \mathrm{~m}^{-2}$. The data were used to derive a canopy surface model (Figure 1, right) with a pixel size of $0.5 \mathrm{~m} \times 0.5 \mathrm{~m}$ as well as area-based metrics characterizing forest density (i.e., the percentage of lidar returns from above certain heights within the canopy) and height (i.e., percentiles of the canopy height distribution) for each $10 \mathrm{~m} \times 10 \mathrm{~m}$ cell of a regular grid imposed on the surface model. The LiDAR metrics were used to produce an above-ground biomass map with a pixel size of $10 \mathrm{~m} \times 10 \mathrm{~m}$ [35]. For the retrieval, a multiple linear regression model, relating the canopy height and density metrics to above-ground biomass, was calibrated with the aid of the forest field inventory plots surveyed in 2010. Variables denoting the forest type (pine, spruce, mixed, young forest) were forwarded as candidate explanatory variables in the regression. Validation with a separate set of seven 0.64-hectare large field plots $(80 \mathrm{~m} \times 80 \mathrm{~m}$ ), which had been established in Remningstorp for the BIOSAR-1 campaign in 2007 and revisited for the BIOSAR-3 campaign in 2010, resulted in an RMSE of $12.7 \%$ with respect to the mean biomass [35].

\subsection{Weather Data}

Weather data from a weather station located $\sim 10 \mathrm{~km}$ east of the test site were obtained from the National Oceanic and Atmospheric Administration, National Climatic Data Center. The data included daily information on minimum and maximum air temperatures, precipitation, and snow depth. Figure 4 illustrates minimum and maximum temperatures as well as the daily precipitation throughout the year 2010. Temperatures were mostly below $0^{\circ} \mathrm{C}$ between January and end of February as well as in December. In March and November, temperatures oscillated around $0{ }^{\circ} \mathrm{C}$. Precipitation was recorded in all months. According to the snow depth measurements, the ground was covered with snow from January to end of March and from mid-November until the end of the year. 


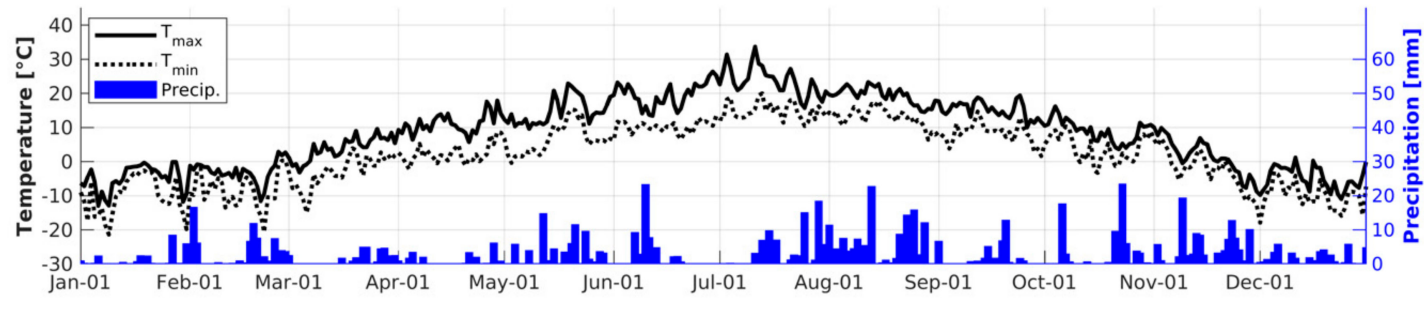

Figure 4. Daily minimum and maximum air temperature and precipitation in 2010 measured at a weather station located close to the test site in Remningstorp.

\section{SAR Dataset}

The SAR dataset consisted of spaceborne and airborne SAR images acquired at C-, L-, and P-bands over the test site during 2010 (Table 1). It comprised 25 C-band images acquired by Radarsat-2 in Wide Fine Quad-Pol mode in winter with look angles ranging from 21 to $41^{\circ}, 17$ ERS-2 C-band images acquired throughout all seasons, 4 ALOS PALSAR Fine-Beam dual-polarization (FBD) L-band images acquired in summer and fall, 2 ALOS PALSAR Fine-Beam single polarization (FBS) L-band images acquired in winter, and fully-polarimetric P-band images acquired in the frame of the BIOSAR-3 campaign by the airborne SAR system SETHI on September 23rd 2010 [35]. The airborne campaign acquired P-band data repeatedly along different flight paths. Imagery from one flight path that covered the majority of the in situ plots (169) was selected.

Pre-processing of the spaceborne imagery aimed at generating a set of co-registered, calibrated, terrain corrected, speckle filtered, and geocoded images. In order to reduce speckle noise and to obtain backscatter images with comparable pixel posting in range and azimuth, the Single Look Complex images acquired by ERS-2, Radarsat-2, and ALOS PALSAR with different range and azimuth resolutions (Table 1) were multi-looked with multi-looking factors in range and azimuth of: $1 \times 6$ (ERS-2), 2-4 5 (Radarsat-2), $3 \times 8$ (PALSAR FBS), and $2 \times 8$ (PALSAR FBD). Images from each sensor were co-registered in slant-range geometry using cross-correlation techniques [37]. Backscatter variations associated with varying pixel scattering areas over sloped terrain were compensated for according to [38]. The multi-channel filter introduced in [39] was applied to reduce speckle. The equivalent number of looks (ENL) of the filtered backscatter images was estimated for a number of homogeneous forest patches with the ratio of the squared mean backscatter to the variance. On average, the ENLs of the filtered ERS-2, Radarsat-2, and ALOS PALSAR images were 18, 34, and 18, respectively. The backscatter images were resampled from radar to map geometry with geocoding lookup tables that were created using orbit information and an elevation model with $50 \mathrm{~m}$ pixel size from the Swedish National Land Survey (Lantmäteriet) [37]. The geocoding entailed an oversampling of the images to $10 \mathrm{~m} \times 10 \mathrm{~m}$ pixel size to match with the pixel size of the airborne data described below.

Table 1. Synthetic aperture radar (SAR) dataset for Remningstorp.

\begin{tabular}{ccccccc}
\hline Band & Sensor & Polarization & Look Angle & $\begin{array}{c}\text { Ground-Range and } \\
\text { Azimuth Resolution }\end{array}$ & No. & $\begin{array}{c}\text { Acquisition } \\
\text { Months }\end{array}$ \\
\hline $\mathbf{C}$ & ERS-2 & $\mathrm{VV}$ & $23^{\circ}$ & $25 \mathrm{~m} \times 4 \mathrm{~m}$ & 17 & $1,3-12$ \\
\hline $\mathbf{C}$ & RADARSAT-2 & $\begin{array}{c}\mathrm{HH}, \mathrm{HV}, \mathrm{VH}, \\
\mathrm{VV}\end{array}$ & $21-41^{\circ}$ & $7-13 \mathrm{~m} \times 5 \mathrm{~m}$ & 25 & $1,2,3,11,12$ \\
\hline $\mathbf{L}$ & $\mathrm{ALOS}$ & $\mathrm{HH}$ & $34^{\circ}$ & $\begin{array}{c}8 \mathrm{~m} \times 3 \mathrm{~m} \\
15 \mathrm{~m} \times 3 \mathrm{~m}\end{array}$ & 2 & 4 \\
\hline $\mathbf{P}$ & PALSAR & $\mathrm{HH}, \mathrm{HV}$ & $34^{\circ}$ & $0,9,10$ \\
\hline \multirow{2}{*}{ SETHI } & $\begin{array}{c}\mathrm{HH}, \mathrm{HV}, \mathrm{VH}, \\
\mathrm{VV}\end{array}$ & $24-62^{\circ}$ & $0.9-2 \mathrm{~m} \times 0.8 \mathrm{~m}$ & 1 & 9 \\
\hline
\end{tabular}

The airborne data had already been pre-processed to calibrated, terrain corrected, and geocoded backscatter images by the data providers [35]. The topographic corrections included a compensation for pixel scattering area variations based on the sine of the local incidence angle. In this study, the 
images with a pixel size of $1 \mathrm{~m} \times 1 \mathrm{~m}$ were spatially averaged to a $10 \mathrm{~m} \times 10 \mathrm{~m}$ pixel size and resampled to the map coordinate system that was used for the spaceborne data. The ENL of the backscatter images with $10 \mathrm{~m}$ pixel size was $\sim 25$.

Local incidence angle maps, $\theta$, were used to convert all backscatter images from $\sigma^{0}$ to $\gamma^{0}$ :

$$
\gamma^{0}=\sigma^{0} / \cos \theta
$$

\section{Methods}

Modelling of the SAR backscatter as a function of total above-ground, stem, and branch biomass has been investigated in the past by means of semi-empirical models [27,40], a wide range of empirical parametric models $[12,14,15,30,31,41]$, as well as non-parametric modeling approaches [42,43]. Based on an extensive survey reported in [1], for this study we selected those presenting the most robust performance across a wide range of imaging conditions.

\subsection{Retrieval Model for C- and L-Band Backscatter}

For the case of C- and L-band, we opted for a water-cloud type of model $[27,40]$ :

$$
\sigma_{f o r}^{0}=\sigma_{g r}^{0} T_{f o r}+\sigma_{v e g}^{0}\left(1-T_{f o r}\right)
$$

in which the backscatter from forested terrain $\sigma^{0}$ for is modeled as the sum of scattering from the forest floor and canopy. The scattering contributions from the forest floor, $\sigma_{g r}^{0}$, and canopy, $\sigma^{0}{ }_{v e g}$, are weighted by the forest transmissivity, $T_{f o r}$. $T_{f o r}$ is expressed a function of the percent canopy cover $\eta$, canopy height $h$, and the two-way signal attenuation within the canopy, $\alpha$ [40]:

$$
T_{f o r}=(1-\eta)+\eta e^{-\alpha h} .
$$

Similar to what was proposed in [44] for the modeling of backscatter as function of biomass, it is assumed that the transmissivity decreases exponentially with increasing above-ground, stem, and branch biomass (i.e., $B_{t}, B_{s}, B_{b}$ ):

$$
T_{f o r}=e^{-\beta_{t, s, b} B_{t, s, b}}
$$

where $\beta_{t, s, b}$ denotes the empirical transmissivity parameter.

The model used for C- and L-band backscatter in Equations (2) and (4) comprises three unknowns: $\sigma_{g r}^{0}, \sigma_{v e g}^{0}$, and $\beta$. These models are typically trained with a least-squares regression using a set of measurements of biomass. When the reference data available consist of measurements taken at small inventory plots, the physical meaning of the model parameters estimates becomes questionable because the observations of the backscatter and the biomass are affected by a large spread [45]. For this reason, it is advised to reduce the numbers of degrees of freedom and opt for a model calibration in which only $\sigma_{g r}^{0}$ and $\sigma_{v e g}^{0}$ are estimated by means of regression and $\beta$ is defined independently from the SAR observations. One possibility is to use LiDAR-driven simulations of the transmissivity, based on Equation (3), where $T_{\text {for }}$ is expressed as a function of canopy cover $\eta$, tree height $h$, and two-way attenuation, $\alpha$. Similar approaches for characterizing the relationship between transmissivity at $C$ - and L-band and forest biophysical parameters (growing stock volume or above-ground biomass) were explored in [44,46-48] for boreal forest sites in Sweden and Siberia as well as temperate forests in the northeastern United States.

Once the model parameters have been estimated for each C- and L-band image in the multi-temporal stack of observations, the model in Equations (2) and (4) is inverted to estimate image-specific total above-ground, stem, and branch biomass: 


$$
B_{t, s, b}=-\beta_{t, s, b}^{-1} \ln \left[\frac{\left[\sigma_{v e g}^{0}-\sigma_{f o r}^{0}\right]}{\left[\sigma_{v e g}^{0}-\sigma_{g r}^{0}\right]}\right] .
$$

Due to the asymptotic shape of the relationship between biomass and SAR backscatter, the inversion necessitated a strategy for dealing with backscatter observations outside the range of modelled backscatter values. Assuming an increasing trend of the backscatter as a function of biomass, a biomass of $0 \mathrm{t} / \mathrm{ha}$ was assigned for backscatter values below $\sigma_{g_{r}}^{0}$. At the other end of the biomass distribution, models were inverted up to the backscatter value corresponding to the highest above-ground, stem, or branch biomass reported in the inventory data, $B_{\max }$. In the retrieval of above-ground biomass, $B_{\max }$ was set to $316 \mathrm{t} / \mathrm{ha}$. In the case of the retrieval of stem and branch biomass, $B_{\max }$ was $257 \mathrm{t} / \mathrm{ha}$ and $59 \mathrm{t} / \mathrm{ha}$, respectively. $B_{\max }$ was associated to all backscatter measurements that were larger than the maximum modeled backscatter.

\subsection{Retrieval Model for P-Band Backscatter}

To model the P-band backscatter as a function of biomass, we opted for an empirical model because (i) the model in Equation (2) neglects double-bounce and multiple scattering contributions, and (ii) a water-cloud model with a multi-path component as proposed in [26] cannot be easily trained and inverted to estimate biomass. The empirical model in Equation (6) relates the backscatter in HV polarization (in $\mathrm{dB}$ ) and the $\mathrm{HH} / \mathrm{VV}$ polarization ratio to the logarithm of biomass:

$$
\log \left(B_{t, s, b}\right)=a_{0}+a_{1} \gamma_{h v}^{0}+a_{2}\left(\gamma_{h h}^{0}-\gamma_{v v}^{0}\right)
$$

where $a_{0}, a_{1}$, and $a_{2}$ are regression parameters to be estimated using a set of in situ measurements of biomass. When assessing the retrieval of above-ground biomass with the P-band data acquired over two forest sites in Sweden (Remningstorp and Krycklan), Soja et al. [31] suggested a similar model, which in addition considered a term related to the slope of the terrain. In Equation (6), this term was neglected since the topography at the test site was mostly flat. The biomass estimates obtained with Equation (6) were bias-corrected when reconverting biomass from logarithmic to linear scale [49].

\subsection{Multi-Image Estimation of Biomass}

Having available multiple estimates of biomass derived from individual scenes, a further estimate can be obtained by combining the individual values in a weighted manner:

$$
B_{m t}=\sum_{i=1}^{N} w_{i} B_{i} / \sum_{i=1}^{N} w_{i}
$$

with

$$
w_{i}=\frac{R M S E_{\text {train }, i}^{-2}}{\sum_{j=1}^{N} R M S E_{\text {train }, j}^{-2} .}
$$

In Equations (7) and (8), subscripts for total above-ground, stem, and branch biomass were omitted for the sake of readability. The weights for each individual scene were defined inversely proportional to the mean square error of the predictions obtained for samples selected for model training. Across the multi-temporal/-frequency/-polarization stack of observations those images were given the most weight that presented the best sensitivity to the biomass variable of interest. To avoid that the artificial estimates of $0 \mathrm{t} / \mathrm{ha}$ or the maximum retrievable biomass, $B_{\max }$, would affect the final estimate of biomass for C- and L-band, an infinitesimal low weight was applied to such values. The artificial estimates were only considered in case none of the images in the stack allowed for a valid estimate. 


\subsection{Retrieval of Aboveground Biomass Via Estimates of Stem and Branch Biomass}

To assess whether an indirect retrieval of above-ground biomass from its components (i.e., stem and branch biomass) would outperform the direct retrieval, we evaluated (i) the sum of estimates of stem and branch biomass [12], and (ii) the above-ground biomass estimated using the branch biomass predicted from the SAR data [14]. For predicting above-ground biomass from radar-derived estimates of branch biomass, a model of the form

$$
B_{t}=\left(a B_{b}\right)^{b}
$$

was fitted to the observed relationships between branch biomass and the total above-ground biomass (Figure 3) to estimate the parameters $a$ and $b$ for each tree species.

\section{Results}

\subsection{Model Calibration}

The water-cloud-type of model in Equations (2) and (4) for C- and L-band, and the empirical model in Equation (6) for P-band were calibrated repeatedly for each backscatter acquisition by means of regression using $67 \%$ of the plots available. The remaining $33 \%$ of plots were used for assessing the retrieval performance. The samples used for training and testing were selected randomly in intervals of biomass to ensure a comparable distribution of biomass in the training and testing datasets. The retrieval accuracies reported in Section 5.2 represent the average of 20 iterations.

In the case of the water-cloud model, only the parameters $\sigma_{g r}^{0}$ and $\sigma^{0}{ }_{v e g}$ were calibrated by means of regression. The transmissivity parameter $\beta$ in Equation (4) was estimated with the aid of LiDAR-based simulations of the transmissivity, $T_{f o r}$, at C- and L-bands. Based on Equation (3), $T_{f o r}$ was simulated as a function of canopy cover $\eta$, tree height $h$, and two-way attenuation, $\alpha$. Canopy cover $\eta$, was estimated for each inventory plot with the percentage of LiDAR returns from heights of more than $2 \mathrm{~m}$ above the forest floor, and $h$ was calculated with the 95th percentile of the vertical distribution of returns. Values for $\alpha$ in the range of 0.5 to $2 \mathrm{~dB} / \mathrm{m}$ were used in the simulation, where $0.5 \mathrm{~dB} / \mathrm{m}$ was considered appropriate for L-band [23,50]. An attenuation of $1 \mathrm{~dB} / \mathrm{m}$ was assumed for C-band images acquired under frozen conditions, $2 \mathrm{~dB} / \mathrm{m}$ for images acquired under unfrozen conditions [47].

In Figure 5, the simulated forest transmissivity is shown as function of total above-ground, stem, and branch biomass of spruce, pine, and deciduous forest, respectively. The figure suggests that a negative exponential relationship exists between transmissivity and each biomass component with different trends depending on tree species. The parameter $\beta$ was estimated by fitting Equation (4) to the observed relationship between transmissivity and above-ground, stem, and branch biomass. Higher values for $\beta$ were obtained for deciduous forest than for coniferous forest. The lowest estimates for $\beta$ in the case of total above-ground and stem biomass were obtained for pine. In the case of branch biomass, the differences between spruce and pine were minor.

Possible ranges for the parameter $\beta$ had so far been investigated primarily with respect to growing stock volume, i.e., the volume of stems per unit area. Values of the order of 0.006 and $0.004 \mathrm{ha} / \mathrm{m}^{3}$ at Cand L-bands, respectively, with some alterations associated with changing imaging conditions had been suggested for boreal forest in $[23,27,44,46,47,51]$. When considering that the wood density for the species in question is in the range of 0.4 to 0.5 , the values for $\beta$ obtained for the case of stem biomass (Figure 5) appear to be in line with those obtained for growing stock volume. 


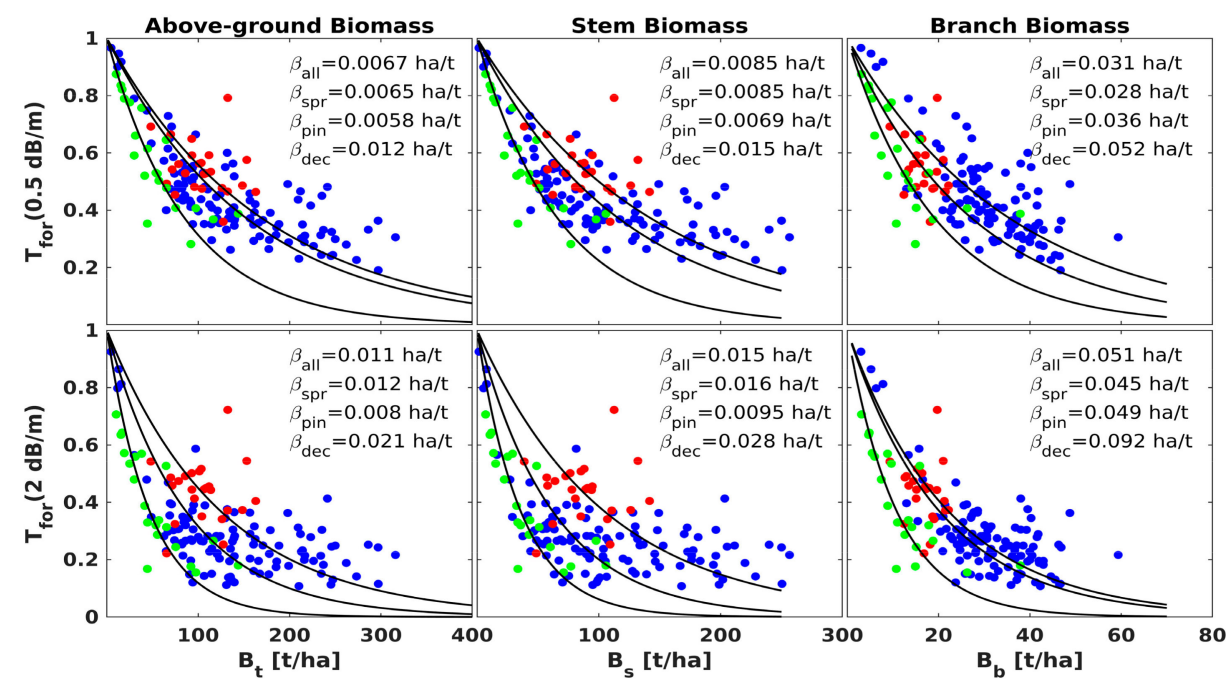

Figure 5. Simulated forest transmissivity for pine (red), spruce (blue), and deciduous (green) forests based on LiDAR-derived height and canopy cover as function of above-ground, stem, and branch biomass.

\subsection{Retrieval of Above-Ground, Stem, and Branch Biomass}

The retrieval of total above-ground, stem, and branch biomass was assessed:

- for each scene in the multi-temporal stack of C-, L-, and P-band observations (Section 5.2.1),

- per frequency/polarization by combining all multi-temporal estimates from backscatter observations at a particular frequency/polarization (Section 5.2.2),

- for different frequency combinations (Section 5.2.3).

We then assessed whether implementing a tree species-specific training of the models in Section 4 improves the retrieval accuracy with respect to a generic training based on all samples available in the dataset of in situ measurements (Section 5.2.4). Based on the derived estimates of stem and branch biomass, we then evaluated if retrieval approaches in which above-ground biomass is estimated via estimates of stem and branch biomass allow for improving the retrieval compared to the direct retrieval of above-ground biomass (Section 5.2.5). Finally, the retrieved biomass with data acquired at a single frequency or at multiple frequencies are compared to the independent dataset of biomass estimates derived from LiDAR (Section 5.2.6). To appreciate the performance of each retrieval, we quantified the retrieval error in the form of the RMSE relative to the mean biomass in the in situ dataset used for validation (RMSEr).

\subsubsection{Single Image Retrieval}

The retrieval performance when using individual scenes for estimating above-ground, stem, and branch biomass at the plot level in Remningstorp depended on the frequency and polarization (Figure 6). For HH, HV, and VH C-band backscatter, the relative RMSE when estimating above-ground and stem biomass was on average of the order of 90 to $100 \%$ (Figure 6). The retrieval error for branch biomass was on average about $10 \%$ lower. In the case of VV polarization, which included the ERS-2 images acquired in all seasons, the error was on average above $100 \%$ for all three biomass variables. The retrieval performance at C-band depended strongly on the imaging conditions and varied in a large range. The highest errors were generally associated with images acquired in periods when snow melts in spring. The lowest errors instead characterized images acquired under stable frozen conditions in winter. The error generally decreased with increasing incidence angle. For Radarsat- 2 images acquired at cross-polarization with steep incidence angles $\left(21^{\circ}\right)$, the retrieval error for aboveground, stem, and branch biomass was, on average, $10 \%$ higher than the error obtained with images acquired at shallow 
incidence angles $\left(41^{\circ}\right)$. In the case of co-polarization, the differences were of the order of $2 \%$. At L-band, the relative RMSE was of the order of $80 \%$ and $90 \%$ when estimating total above-ground and stem biomass, respectively. For branch biomass, the error approached 60\% (Figure 6). Differently than at C-band, the errors remained rather constant in time and varied by less than $10 \%$, except for two estimates of branch biomass using $\mathrm{HH}$-polarized images acquired under frozen conditions in winter, which were characterized by an approximately 20\% larger retrieval error (Figure 6). The stem biomass retrieval, instead, was not affected by the frozen conditions. In the case of P-band, the relative RMSEs for total above-ground, stem, and branch biomass were $42 \%, 45 \%$, and $41 \%$, respectively (Figure 6).
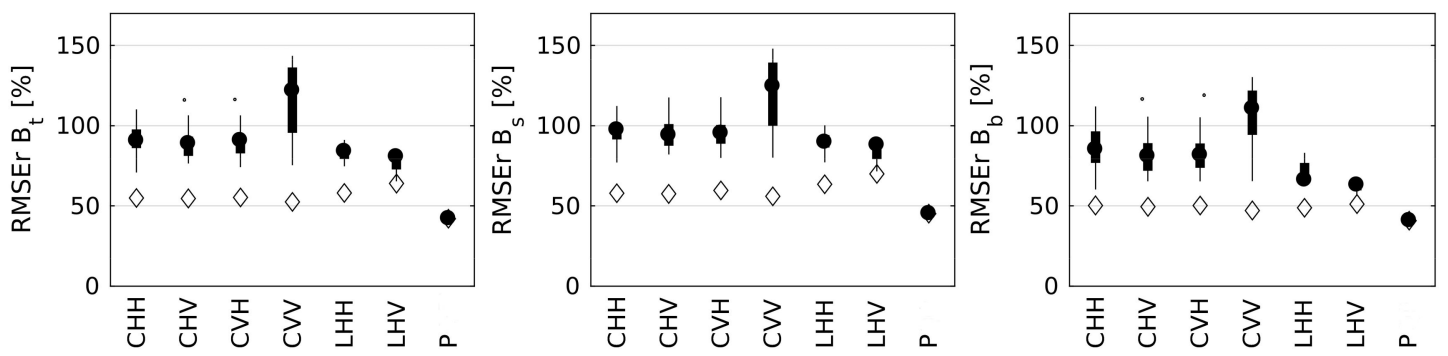

Figure 6. Relative RMSE (RMSEr) of above-ground (left), stem (center), and branch (right) biomass with respect to the inventory at plot level for single- and multi-image retrieval. Retrieval statistics are grouped for each given combination of frequency and polarization. In the case of P-band, a retrieval model based on $\mathrm{HH}, \mathrm{VV}$, and $\mathrm{HV}$ polarizations was used, which is why results are not reported per polarization. For the single-image retrievals, the black circles denote the median RMSEr, the thick lines represent the inter-quartile range of RMSEr, and the thin lines the span of RMSEr values. The diamonds $(\diamond)$ denote the multi-temporal retrieval RMSEr.

\subsubsection{Multi-Temporal Retrieval}

The retrieval performance improved both at C-and L-bands when combining all single image estimates per polarization with Equations (7) and (8). The accuracy of the multi-temporal retrieval results for each frequency and polarization are shown in Figure 6 (diamonds). The multi-temporal combination of C-band derived estimates of above-ground, stem, and branch biomass, respectively, resulted in relative RMSEs of 52-55\% (above-ground), 56-60\% (stem), and 47-50\% (branch) for the different polarizations. In the case of L-HH, the relative RMSEs improved to $58 \%, 63 \%$, and $49 \%$; in the case of L-HV to $64 \%, 70 \%$, and $51 \%$ for above-ground, stem, and branch biomass, respectively. Since only a single acquisition was available, the benefit of combining multi-temporal observations could not be evaluated in the case of P-band.

\subsubsection{Multi-Frequency Retrieval}

Total above-ground, stem, and branch biomass were estimated using all possible combinations of frequencies in order to identify the set of frequencies that allow for the best possible retrieval accuracy. Figure 7 illustrates the retrieval performance in terms of the relative RMSE when combining individual estimates of above-ground, stem, or branch biomass from all available (i) C-band, (ii) C- and L-band, (iii) C- and P-band, (iv) L-band, (v) L- and P-band, (vi) P-band, and (vii) C-, L-, and P-band backscatter images based on Equations (7) and (8). 


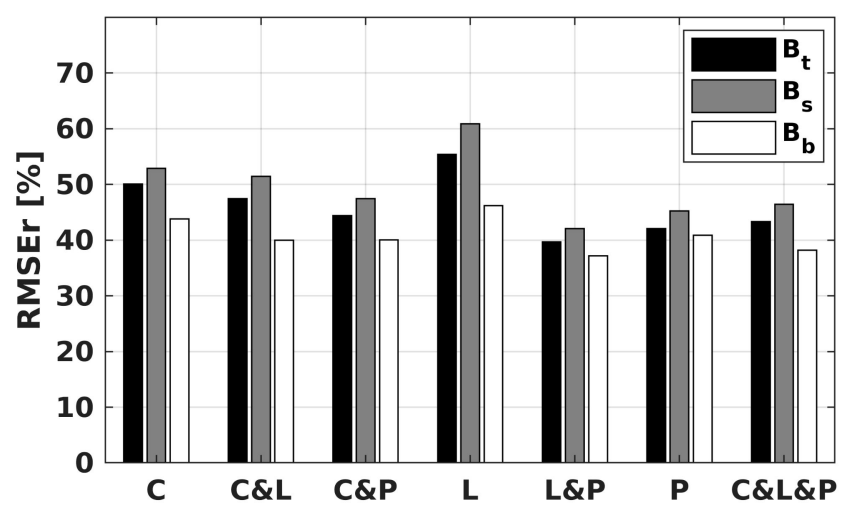

Figure 7. Relative RMSE for estimates of total above-ground, stem, and branch biomass derived from different combinations of multi-temporal C-, L-, and P-bands.

The highest accuracy for all three biomass variables were achieved using L- and P-band backscatter jointly. The relative RMSE for total above-ground, stem, and branch biomass improved to $40 \%, 42 \%$, and $37 \%$, respectively, and was therefore about 2 to $4 \%$ better than the retrieval solely based on P-band. Adding C-band to the stack of L- and P-band observations did not improve the retrieval performance. On the other hand, the combined use of C- and L-bands improved the retrieval performance (RMSEr: $47 \%, 51 \%, 40 \%$ ) compared to the C- (RMSEr: 50\%, 53\%, 43\%) and L-band (RMSEr: 55\%, 61\%, 46\%) only cases.

\subsubsection{Retrieval per Species}

The retrieval with multi-temporal L- and P-band backscatter could be further improved when calibrating the models presented in Section 4 separately for spruce, pine, and deciduous forest (Figure 8). Calibrating separate models implied that the relative RMSE decreased from $40 \%, 42 \%$, and $37 \%$ to $37 \%$, $40 \%$, and $31 \%$ for above-ground, stem, and branch biomass, respectively. The largest improvements were observed for pine. The relative RMSE for the estimates of total above-ground, stem, and branch biomass of pine decreased from $35 \%, 34 \%$, and $45 \%$ to $24 \%, 25 \%$, and $25 \%$, respectively. In deciduous forest, the relative RMSE decreased from $71 \%, 74 \%$, and $71 \%$ to $67 \%, 70 \%$, and $57 \%$, respectively. In the case of spruce, the retrieval error remained unchanged (RMSEr of $37 \%, 40 \%, 29 \%$ ). 

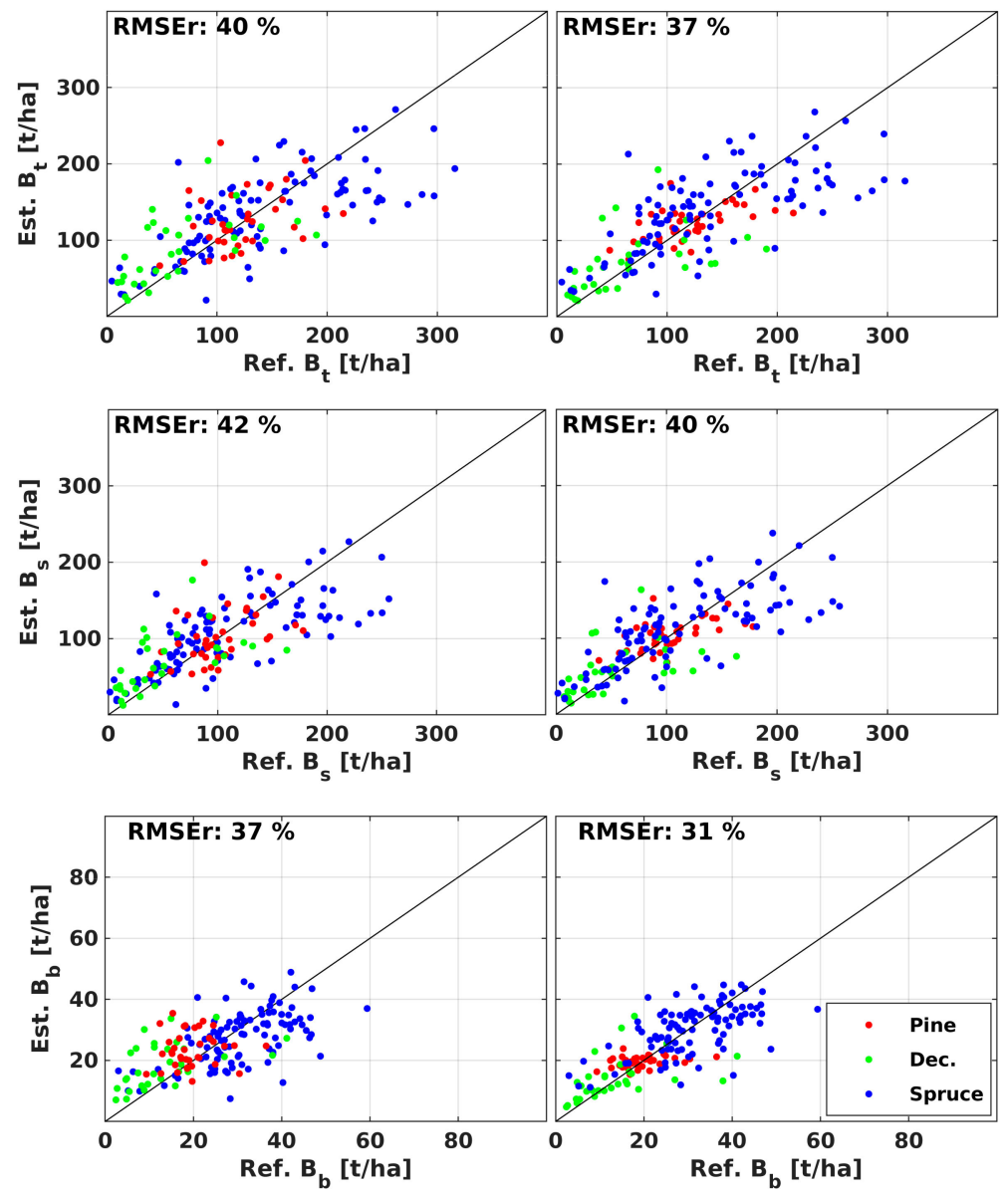

Figure 8. Comparison of in situ plot-level values of above-ground, stem, and branch biomass with radar-derived estimates obtained without (left column) or with (right column) consideration of species in the model calibration.

\subsubsection{Direct vs Indirect Retrieval of Above-Ground Biomass}

To assess whether an indirect retrieval of aboveground biomass from its components would outperform the direct retrieval, we evaluated (i) the sum of the estimated stem and branch biomass, and (ii) the above-ground biomass estimated with Equation (9) using the branch biomass predicted from the SAR data against the direct estimates of above-ground biomass.

When calibrating models separately for spruce, pine, and deciduous forests, the sum of independent stem and branch biomass estimates derived from multi-temporal L- and P-band backscatter yielded almost identical above-ground biomass estimates as the direct retrieval. The relative RMSE of the retrieved above-ground biomass compared to the in situ observations was 37\% (Figure 9, left), thus being almost identical to the value obtained when estimating above-ground biomass directly from the SAR data (Figure 8, upper right). 

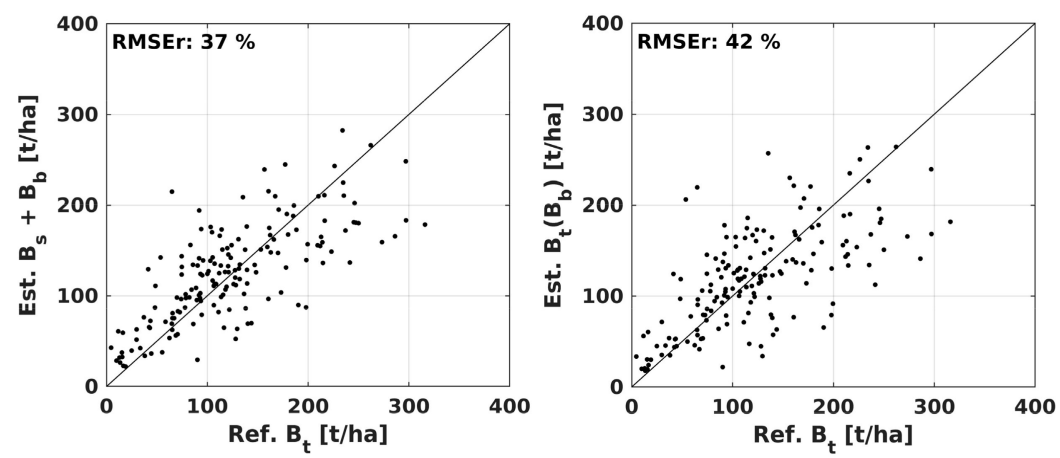

Figure 9. Comparison of in situ above-ground biomass with estimates obtained by summing independent radar-derived stem and branch biomass estimates (left), or by applying allometric relationships between radar-derived branch and above-ground biomass (right).

For converting estimates of branch biomass derived from multi-temporal L- and P-band backscatter to above-ground biomass, the parameters $a$ and $b$ in Equation (9) were estimated by fitting the allometric function to the observed relationship between branch and above-ground biomass shown in Figure 3 (spruce: $a=0.79, b=1.53$; pine: $a=7.73, b=0.96$; deciduous: $a=9.41, b=0.88$ ). When applying the allometric relationships to convert the radar-derived branch biomass estimates to above-ground biomass, the error was $42 \%$ (Figure 9, right) and thus 5\% larger than in the case of the direct retrieval.

\subsubsection{Comparison with LiDAR-Derived Above-Ground Biomass}

Radar-derived above-ground biomass estimates were finally compared against the LiDAR-derived biomass map to verify that observations at the scale of the inventory plots are consistent with a spatially explicit dataset of biomass even if compiled at coarser spatial resolution. Similar to what was done at plot-level (Section 5.2.3), the retrieval of above-ground biomass with the radar data was carried out repeatedly to test the retrieval performance for all possible combinations of multi-temporal C-, L-, and P-band backscatter after aggregating all backscatter images as well as the LiDAR map to $100 \mathrm{~m} \times 100$ $\mathrm{m}$ pixel size. The one-hectare scale was selected to allow for reduction of pixel-wise noise in each of the datasets being compared so to be able to identify major systematic differences.

Figure 10 illustrates the relationship of radar- and LiDAR-derived estimates of above-ground biomass for four (out of the seven tested) retrieval scenarios (cf., Section 5.2.3), i.e., a retrieval based on (i) P-band backscatter (top left), (ii) multi-temporal L-band backscatter (top right), (iii) multi-temporal L- and C-band backscatter (bottom left), and (iv) all available P-, L-, and C-band backscatter images (bottom right). Across all possible combinations, the lowest error of $28 \%$ was achieved when combining estimates obtained from SAR backscatter acquired at the three frequencies considered in this study (Figure 10, bottom right). The retrieval with P-band only resulted in a relative RMSE of 32\% (Figure 10, upper left). The combination of multi-temporal L- and C-bands resulted in an error of 32\% (Figure 10, bottom left) and clearly reduced the retrieval error compared to retrieval with multi-temporal L- or C-bands separately, for which the relative RMSEs were 39\% and 51\%, respectively. In line with what was observed at plot level (Figure 6), we found that the availability of multi-temporal observations for the retrieval with C- and L-bands was crucial. Across all biomass estimates derived from individual Cor L-band backscatter images, the lowest error of $61 \%$ was associated with a cross-polarization L-band backscatter image acquired in August. 

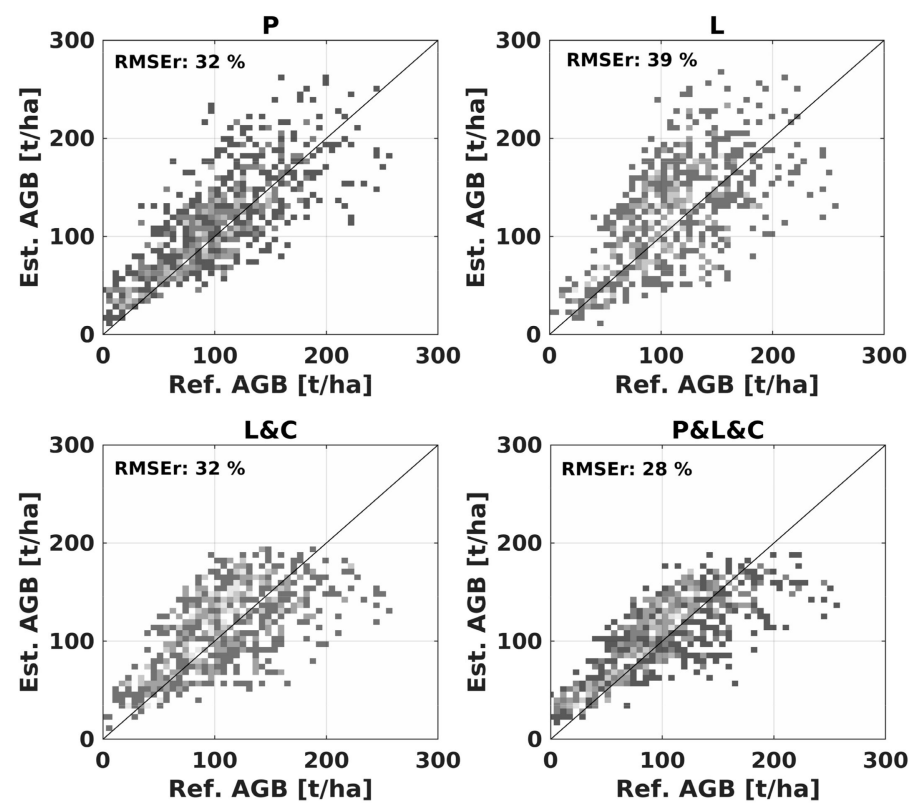

Figure 10. Comparison of LiDAR-derived above-ground biomass (AGB) estimates with estimates obtained with different combinations of multi-temporal C-, L-, and P-band backscatter at the one-hectare scale.

The results generally confirmed the indications obtained from the analysis undertaken at the level of inventory plots. The combination of P-band with multi-temporal C- and L-bands allows for only minor improvements of $4 \%$ compared to the retrieval with P-band only; nonetheless, multi-temporal C- and L-band observations of the SAR backscatter allow for estimating above-ground biomass with accuracies close to those achieved with a single P-band observation.

\section{Discussion}

The retrieval performance when using different combinations of multi-temporal C-, L-, and P-band images was assessed with the aid of forest inventory plots and a LiDAR-derived biomass map with $100 \mathrm{~m} \times 100 \mathrm{~m}$ pixel size. The retrieval with a single P-band observation resulted in an error of $32 \%$ at hectare-scale (Figure 10) and $42 \%$ at the scale of the plots in terms of the relative RMSE (Figure 6). Multi-temporal C- and L-band data allowed for estimating above-ground biomass with errors of $51 \%$ and $39 \%$ at the hectare scale and $50 \%$ and $55 \%$ at plot scale, respectively. When combining P-band with multi-temporal backscatter observations acquired at higher frequencies, the error could be improved by $2 \%$ at plot- (Figure 7 ) and $4 \%$ at hectare-scale (Figure 10). The results confirm that P-band is the most suited frequency for estimating above-ground biomass and indicate that only limited improvements can be achieved by combining P-band backscatter with observations acquired at higher frequencies. When combined, however, C- and L-bands allowed for retrieving above-ground biomass with comparable accuracy as a single P-band observation, provided that multi-temporal observations are available. The combined use of multi-temporal C- and L-band resulted in retrieval errors of $32 \%$ at the hectare scale and $47 \%$ at the plot scale. Multi-temporal coverage was crucial at both frequencies since the retrieval with single C- or L-band observations, even when acquired under preferable imaging conditions, resulted in poor accuracies (Figure 6). The effect of varying environmental imaging conditions and the importance of using multi-temporal observations for the retrieval with C- or L-band have been analyzed for different sites in the boreal and boreal-temperate transition zone in Sweden, Finland, Siberia, or the northeastern United States [16,27-29,51-53]. All studies confirmed that the imaging conditions strongly affected the backscatter to biomass relationships and the potential to estimate biomass from individual backscatter images. The seasonal alterations in the backscatter to biomass relationships due to changes in soil moisture, plant water status, or freeze/thaw transitions, as well as 
the conditions for which C- or L-band backscatter presented the highest sensitivity to biomass were found to differ between the different boreal forest sites [27,45]. The integration of multi-temporal observations in the retrieval has proven to be an effective approach for reducing/compensating for such local differences and to produce biomass maps with consistent accuracy across larger areas [48,52]. In the case of L-band, the multi-temporal retrieval of above-ground biomass, or the closely related parameter growing stock volume, at different forest sites in the boreal zone achieved accuracies mostly in the range of $25 \%$ to $45 \%$ at the scale of forest stands with sizes above 1 hectare $[4,16,27,29,53,54]$. The differences in the reported accuracies between the sites may be associated with variable numbers of available backscatter images, the lack of backscatter images acquired under what may be considered "optimal" conditions at a particular forest site, or forest structural differences [27,48]. The results of this study advocate a combined use of multi-temporal L- and C-band backscatter as a means to further improve the robustness of L-band retrievals of biomass with respect to spatially and temporally varying environmental imaging conditions. Due to the limited number of P-band imagery that has been acquired by airborne campaigns, limited experience has so far been gathered on the temporal stability of the P-band backscatter to biomass relationship and the advantage of having multi-temporal P-band observations [30,32]. A comparison of several P-band backscatter images acquired over a period of two months in late winter and spring over Remningstorp suggested very high temporal consistency of the measurements [30], i.e., the availability of multi-temporal data may be less crucial.

The retrieval could be improved when accounting for structural differences between pine, spruce, and deciduous forests in Remningstorp in the modeling of C-, L-, and P-band backscatter as a function of above-ground biomass (Figure 8). The structural differences between species revealed in form of (i) different proportions of biomass in stems and branches at comparable levels of total above-ground biomass for pine and spruce (Figure 2), and (ii) different relationships between the transmissivity (simulated with the aid of the LiDAR data) at C- and L-band and above-ground biomass (Figure 5). The improvements when using L- and P-band were most pronounced for pine-dominated stands, for which the retrieval error in terms of the relative RMSE reduced for $11 \%$ (RMSEr of 35\% vs $24 \%$ ). In the case of deciduous forest, the improvements were of the order of $4 \%$ (RMSEr of $71 \%$ vs $67 \%$ ). In the case of spruce, i.e., the most abundant species in the test area, no improvements were achieved (RMSEr of 37\%), presumably because the retrieval when not considering species was mostly optimized for spruce. Since structural differences between species are generally not known a priori when mapping above-ground biomass with radar, new approaches for optimizing the retrieval with respect to differences in forest structure need to be explored.

We investigated whether approaches in which above-ground biomass is estimated via independent radar-derived estimates of branch and/or stem biomass [12,14] are better suited for exploiting the complementarity of information on forest structure and biomass contained in multi-frequency radar backscatter than approaches aiming directly for the estimation of above-ground biomass. When comparing the retrieval performance for branch, stem, and above-ground biomass based on those backscatter images in the multi-temporal and multi-frequency stack of observations with maximum sensitivity to the biomass component in question, we found that the retrieval of branch biomass outperformed the retrieval of stem and above-ground biomass. When using L- and P-bands, the relative RMSE at plot-level was 31\% in the case of branch biomass, $40 \%$ in the case of stem biomass, and $37 \%$ in the case of above-ground biomass (Figure 8); note that branch biomass was estimated with higher accuracy than stem or above-ground biomass regardless of the combination of frequencies that were used (Figure 7). In line with what was reported in [14], the retrieval results suggested that the radar signals primarily sense the canopy and that radar-derived estimates of total above-ground biomass, in essence, reflect the allometric relationship between branch and total above-ground biomass. However, the retrieval of above-ground biomass via radar-derived branch biomass estimates and allometric models relating branch to above-ground biomass [14] was found to perform 5\% worse than the retrieval in which multi-frequency backscatter is used to estimate above-ground biomass directly (Figure 9). This result may be seen as an indication that there is information on above-ground 
biomass in the backscatter measurements that do not only reflect the biomass contained in the canopy. The test of a retrieval approach in which independent radar-derived estimates of stem and branch biomass are summed [12] seemed to confirm this interpretation. With this approach, above-ground biomass estimates were obtained with an error that was 5\% lower than that obtained when estimating above-ground biomass via radar-derived branch biomass and allometric models (Figure 9). Overall, the results did not suggest that the retrieval of above-ground biomass can be improved by estimating above-ground biomass via radar-derived estimates of stem and/or branch biomass since none of the two "indirect" approaches outperformed the direct retrieval of above-ground biomass.

\section{Conclusions}

In this study, we investigated the benefit of combining multiple backscatter observations acquired at C-, L-, and P-bands for the retrieval of above-ground biomass over a forest site in southern Sweden. In particular, the scope was to benchmark P-band only retrievals with retrievals adding observations at short wavelengths. When using the different frequencies separately, P-band backscatter allowed for estimating above-ground biomass with the lowest error of the order of $30 \%$ at the hectare scale and $40 \%$ at the level of forest inventory plots. The retrieval with multi-temporal L- and C-bands was instead characterized by errors of the order of $40 \%$ and $50 \%$ at the hectare scale, respectively. The results therefore reconfirmed that P-band is the most suited frequency for estimating above-ground biomass. Complementing P-band retrievals of biomass with multi-temporal C-and L-band observations did not allow for major improvements of the retrieval accuracy. However, we found that the combination of multi-temporal C- and L-band backscatter allowed for retrieval accuracies close to those achieved with single P-band observations. Further tests at other boreal forest sites (for instance at less managed forest sites) are advised to evaluate if the mapping of biomass with multi-temporal C-and L-band backscatter with error levels comparable to those obtained for Remningstorp (i.e., 30\%) is possible across larger boreal areas. Nonetheless, the results of this study clearly demonstrate that it is worthwhile to exploit the abundance of C- and L-band data to be acquired globally in the years to come by existing and planned missions such as the ESA Sentinel-1, Radarsat Constellation, JAXA ALOS-2 and ALOS-4, or NASA-ISRO NiSAR missions for the mapping of above-ground biomass, even after the launch of the ESA BIOMASS mission. The use of C- and L-band data may be a viable option for (i) mapping above-ground biomass in areas where the BIOMASS mission will not be able to acquire data, e.g., in boreal North America and Europe [55], and (ii) tracking changes in biomass over several decades of Cand L-band observations.

Supplementary Materials: The following are available online at http://www.mdpi.com/2072-4292/11/14/1695/s1.

Author Contributions: O.C. and M.S. designed the study; U.W. processed the spaceborne radar imagery; O.C. carried out the data analysis and biomass retrieval; O.C., M.S., U.W., and B.R. wrote and revised the paper.

Funding: This study was funded by the European Space Agency (Contract 4000115192/15/NL/AF/eg).

Acknowledgments: The ESA campaign data was accessed through Cat-1 project 33648, Radarsat-2 data through ESA Cat-1 TPM project 34516, and ERS-2 data through ESA Cat-1 project 15209. The ALOS PALSAR data were obtained from JAXA in the frame of the ALOS Calibration/Validation activities. Weather data from the Global Historical Climatology Network were obtained through the NOAA National Climatic Data Center.

Conflicts of Interest: The authors declare no conflict of interest. The funders had no role in the design of the study; in the collection, analyses, or interpretation of data; in the writing of the manuscript; or in the decision to publish the results.

\section{References}

1. Santoro, M.; Cartus, O. Pathways of forest above-ground biomass estimation with SAR backscatter and interferometric SAR observations. Remote Sens. 2018, 10, 608. [CrossRef]

2. Bouvet, A.; Mermoz, S.; Le Toan, T.; Villard, L.; Mathieu, R.; Naidoo, L.; Asner, G.P. An above-ground biomass map of African savannahs and woodlands at $25 \mathrm{~m}$ resolution derived from ALOS PALSAR. Remote Sens. Environ. 2018, 206, 156-173. [CrossRef] 
3. Santoro, M.; Beaudoin, A.; Beer, C.; Cartus, O.; Fransson, J.E.S.; Hall, R.; Pathe, C.; Schepaschenko, D.; Schmullius, C.C.; Shvidenko, A.; et al. Forest growing stock volume of the northern hemisphere: Spatially explicit estimates for 2010 derived from Envisat ASAR data. Remote Sens. Environ. 2015, 168, 316-334. [CrossRef]

4. Antropov, O.; Rauste, Y.; Häme, T.; Praks, J. Polarimetric ALOS PALSAR Time Series in Mapping Biomass of Boreal Forests. Remote Sens. 2017, 9, 999. [CrossRef]

5. Quegan, S.; Le Toan, T.; Chave, J.; Dall, J.; Exbrayat, J.F.; Minh, D.H.T.; Rocca, F. The European Space Agency BIOMASS mission: Measuring forest above-ground biomass from space. Remote Sens. Environ. 2019, 227, 44-60. [CrossRef]

6. Wang, Y.; Davis, F.W.; Melack, J.M. The effects of changes in forest biomass on radar backscatter from tree canopies. Int. J. Remote Sens. 1995, 16, 503-513. [CrossRef]

7. Lucas, R.M.; Moghaddam, M.; Cronin, N. Microwave scattering from mixed-species forests, Queensland, Australia. IEEE Trans. Geosci. Remote Sens. 2004, 42, 2142-2159. [CrossRef]

8. Chauhan, N.S.; Lang, R.; Ranson, K.J. Radar Modeling of a Boreal Forest. IEEE Trans. Geosci. Remote Sens. 2004, 29, 627-638. [CrossRef]

9. Freeman, A.; Durden, S.L. A three-component scattering model for polarimetric SAR data. IEEE Trans. Geosci. Remote Sens. 1998, 36, 963-973. [CrossRef]

10. Lang, R.; Chauhan, N.S.; Ranson, K.J.; Kilic, O. Modeling P-band SAR returns from a red pine stand. Remote Sens. Environ. 1994, 47, 132-141. [CrossRef]

11. Ranson, K.J.; Sun, G. Northern forest classification using temporal multifrequency and multipolarimetric SAR images. Remote Sens. Environ. 1994, 47, 142-153. [CrossRef]

12. Dobson, M.C.; Ulaby, F.T.; Pierce, L.E.; Sharik, T.L.; Bergen, K.M.; Kellndorfer, J.; Sarabandi, K. Estimation of Forest Biophysical Characteristics in Northern Michigan with SIR-C/X-SAR. IEEE Trans. Geosci. Remote Sens. 1995, 33, 877-895. [CrossRef]

13. Harrell, P.A.; Bourgeau-Chavez, L.L.; Kasischke, E.S.; French, N.H.F.; Christensen, N.L. Sensitivity of ERS-1 and JERS-1 radar data to biomass and stand structure in Alaskan boreal forest. Remote Sens. Environ. 1995, 54, 247-260. [CrossRef]

14. Kasischke, E.S.; Christensen, N.L.; Bourgeau-Chavez, L.L. Correlating Radar Backscatter with Components of Biomass in Loblolly Pine Forests. IEEE Trans. Geosci. Remote Sens. 1995, 33, 643-659. [CrossRef]

15. Saatchi, S.S.; Halligan, K.; Despain, D.G.; Crabtree, R.L. Estimation of forest fuel load from radar remote sensing. IEEE Trans. Geosci. Remote Sens. 2007, 45, 1726-1740. [CrossRef]

16. Kurvonen, L.; Pulliainen, J.T.; Hallikainen, M.T. Retrieval of biomass in boreal forests from multitempotal ERS-1 and JERS-1 SAR images. IEEE Trans. Geosci. Remote Sens. 1999, 37, 198-205. [CrossRef]

17. Englhart, S.; Keuck, V.; Siegert, F. Aboveground biomass retrieval in tropical forests-The potential of combined X- and L-band SAR data use. Remote Sens. Environ. 2011, 115, 1260-1271. [CrossRef]

18. Tsui, O.W.; Coops, N.C.; Wulder, M.A.; Marshall, P.L.; McCardle, A. Using multi-frequency radar and discrete-return LiDAR measurements to estimate above-ground biomass and biomass components in a coastal temperate forest. ISPRS J. Photogramm. Remote Sens. 2012, 69, 121-133. [CrossRef]

19. Harrell, P.A.; Kasischke, E.S.; Bourgeau-Chavez, L.L.; Haney, E.M.; Christensen, N.L. Evaluation of approaches to estimating aboveground biomass in southern pine forests using SIR-C data. Remote Sens. Environ. 1997, 59, 223-233. [CrossRef]

20. Santi, E.; Paloscia, S.; Pettinato, S.; Fontanelli, G.; Mura, M.; Zolli, C.; Chirici, G. The potential of multifrequency SAR images for estimating forest biomass in Mediterranean areas. Remote Sens. Environ. 2017, 200, 63-73. [CrossRef]

21. Ranson, K.J.; Sun, G.; Weishampel, J.F.; Knox, R.G. Forest biomass from combined ecosystem and radar backscatter modeling. Remote Sens. Environ. 1997, 59, 118-133. [CrossRef]

22. Kasischke, E.S.; Bourgeau-Chavez, L.L.; Christensen, N.L.; Haney, E.M. Observations on the sensitivity of ERS-1 sar image intensity to changes in aboveground biomass in young loblolly pine forests. Int. J. Remote Sens. 1994, 15, 3-16. [CrossRef]

23. Askne, J.I.H.; Santoro, M.; Smith, G.; Fransson, J.E.S. Multitemporal repeat-pass SAR interferometry of boreal forests. IEEE Trans. Geosci. Remote Sens. 2003, 41, 1540-1550. [CrossRef] 
24. Pulliainen, J.T.; Mikkela, P.J.; Hallikainen, M.T.; Ikonen, J.P. Seasonal dynamics of C-band backscatter of boreal forests with applications to biomass and soil moisture estimation. IEEE Trans. Geosci. Remote Sens. 1996, 34, 758-770. [CrossRef]

25. Ranson, K.J.; Sun, G. Effects of environmental conditions on boreal forest classification and biomass estimates with SAR. IEEE Trans. Geosci. Remote Sens. 2000, 38, 1242-1252. [CrossRef]

26. Pulliainen, J.T.; Kurvonen, L.; Hallikainen, M.T. Multitemporal behavior of L-and C-band SAR observations of boreal forests. IEEE Trans. Geosci. Remote Sens. 1999, 37, 927-937. [CrossRef]

27. Santoro, M.; Eriksson, L.E.B.; Askne, J.I.H.; Schmullius, C.C. Assessment of stand-wise stem volume retrieval in boreal forest from JERS-1 L-band SAR backscatter. Int. J. Remote Sens. 2006, 27, 3425-3454. [CrossRef]

28. Santoro, M.; Fransson, J.E.S.; Eriksson, L.E.B.; Magnusson, M.; Ulander, L.M.H.; Olsson, H. Signatures of ALOS PALSAR L-band backscatter in Swedish Forest. IEEE Trans. Geosci. Remote Sens. 2009, 47, 4001-4019. [CrossRef]

29. Santoro, M.; Eriksson, L.E.B.; Fransson, J.E.S. Reviewing ALOS PALSAR backscatter observations for stem volume retrieval in Swedish forest. Remote Sens. 2015, 7, 4290-4317. [CrossRef]

30. Sandberg, G.; Ulander, L.M.H.; Fransson, J.E.S.; Holmgren, J.; Le Toan, T. L-and P-band backscatter intensity for biomass retrieval in hemiboreal forest. Remote Sens. Environ. 2011, 115, 2874-2886. [CrossRef]

31. Soja, M.J.; Sandberg, G.; Ulander, L.M.H. Regression-based retrieval of boreal forest biomass in sloping terrain using P-band SAR backscatter intensity data. IEEE Trans. Geosci. Remote Sens. 2013, 51, 2646-2665. [CrossRef]

32. Dubois-Fernandez, P.C.; Le Toan, T.; Daniel, S.; Oriot, H.; Chave, J.; Blanc, L.; Petit, M. The tropiSAR airborne campaign in French Guiana: Objectives, description, and observed temporal behavior of the backscatter signal. IEEE Trans. Geosci. Remote Sens. 2012, 50, 3228-3241. [CrossRef]

33. Rignot, E.; Zimmermann, R.; van Zyl, J.J. Spaceborne Applications of P Band Imaging Radars for Measuring Forest Biomass. IEEE Trans. Geosci. Remote Sens. 1995, 33, 1162-1169. [CrossRef]

34. Hajnsek, I.; Scheiber, R.; Ulander, L.; Gustavsson, A.; Sandberg, G.; Tebaldini, S.; Pardini, M. BIOSAR 2008 Technical Assistance for the Development of Airborne SAR and Geophysical Measurements during the BioSAR 2008 Experiment; Final Report; ESA: Paris, France, ESA Contract No. 20755/07/NL/CB; 2009.

35. Ulander, L.M.H.; Gustavsson, A.; Flood, B.; Murdin, D.; Dubois-Fernandez, P.; Depuis, X.; Holmgren, J. BioSAR 2010-Technical Assictance for the Development of Airborne SAR and Geophysical Measurements during the BioSAR 2010 Experiment; Final Report; ESA: Paris, France, ESA Contract No.: 4000102285/10/NL/JA/ef; 2011.

36. Petersson, H. Biomassafunktioner för trädfaktorer av tall, gran och björk $i$ Sverige; Rapport 59; Sveriges lantbruksuniversistet Uppsala, Institutionen för Resurshushallning och Geomatik: Böblingen, Germany, 1999.

37. Wegmüller, U. Automated terrain corrected SAR geocoding. In Proceedings of the IEEE 1999 International Geoscience and Remote Sensing Symposium, IGARSS'99, Hamburg, Germany, 28 June-2 July 1999.

38. Frey, O.; Santoro, M.; Werner, C.L.; Wegmüller, U. DEM-Based SAR Pixel-Area Estimation for Enhanced Geocoding Refinement and Radiometric Normalization. IEEE Geosci. Remote Sens. Lett. 2013, 10, 48-52. [CrossRef]

39. Quegan, S.; Yu, J.J. Multichannel Filtering of SAR Images. IEEE Trans. Geosci. Remote Sens. 2001, 39, 2371-2379. [CrossRef]

40. Askne, J.I.H.; Dammert, P.B.G.; Ulander, L.M.H.; Smith, G. C-band repeat-pass interferometric SAR observations of the forest. IEEE Trans. Geosci. Remote Sens. 1997, 35, 25-35. [CrossRef]

41. Imhoff, M.L. Radar backscatter and biomass saturation: Ramifications for global biomass inventory. IEEE Trans. Geosci. Remote Sens. 1995, 33, 511-518. [CrossRef]

42. Breiman, L. Random forests. Mach. Learn. 2001, 45, 5-32. [CrossRef]

43. Tanase, M.A.; Panciera, R.; Lowell, K.; Tian, S.Y.; Garcia-Martin, A.; Walker, J.P. Sensitivity of L-Band Radar Backscatter to Forest Biomass in Semiarid Environments: A Comparative Analysis of Parametric and Nonparametric Models. IEEE Trans. Geosci. Remote Sens. 2014, 52, 4671-4685. [CrossRef]

44. Santoro, M.; Askne, J.I.H.; Smith, G.; Fransson, J.E.S. Stem volume retrieval in boreal forests from ERS-1 / 2 interferometry. Remote Sens. Environ. 2002, 81, 19-35. [CrossRef]

45. Santoro, M.; Cartus, O.; Fransson, J.E.S.; Wegmüller, U. Complementarity of X-, C-and L-band SAR backscatter observations to retrieve forest stem volume. Remote Sens. 2019, 11, 1563. [CrossRef] 
46. Cartus, O.; Santoro, M.; Schmullius, C.C.; Li, Z. Large area forest stem volume mapping in the boreal zone using synergy of ERS-1/2 tandem coherence and MODIS vegetation continuous fields. Remote Sens. Environ. 2011, 115, 931-943. [CrossRef]

47. Santoro, M.; Shvidenko, A.; McCallum, I.; Askne, J.I.H.; Schmullius, C.C. Properties of ERS-1/2 coherence in the Siberian boreal forest and implications for stem volume retrieval. Remote Sens. Environ. 2007, 106, 154-172. [CrossRef]

48. Cartus, O.; Santoro, M.; Kellndorfer, J.M. Mapping forest aboveground biomass in the Northeastern United States with ALOS PALSAR dual-polarization L-band. Remote Sens. Environ. 2012, 124, 466-478. [CrossRef]

49. Newman, M.C. Regression analysis of log-transformed data: Statistical bias and its correction. Environ. Toxicol. Chem. 1993, 12, 1129-1133. [CrossRef]

50. Praks, J.; Antropov, O.; Hallikainen, M.T. LIDAR Aided SAR Interferometry Studies in Boreal Forest: Phase Center and Extinction Coefficient at X- and L-band. Trans. Geosci. Remote Sens. 2011, 50, 3831-3843. [CrossRef]

51. Askne, J.I.H.; Santoro, M. Multitemporal repeat pass SAR interferometry of boreal forests. IEEE Trans. Geosci. Remote Sens. 2005, 43, 1219-1228. [CrossRef]

52. Santoro, M.; Beer, C.; Cartus, O.; Schmullius, C.; Shvidenko, A.; McCallum, I.; Wiesmann, A. Retrieval of growing stock volume in boreal forest using hyper-temporal series of Envisat ASAR ScanSAR backscatter measurements. Remote Sens. Environ. 2011, 115, 490-507. [CrossRef]

53. Antropov, O.; Rauste, Y.; Ahola, H.; Häme, T. Stand-level stem volume of boreal forests from spaceborne SAR imagery at L-band. IEEE J. Sel. Top. Appl. Earth Observ. Remote Sens. 2013, 6, 35-44. [CrossRef]

54. Peregon, A.; Yamagata, Y. The use of ALOS/PALSAR backscatter to estimate above-ground forest biomass: A case study in Western Siberia. Remote Sens. Environ. 2013, 137, 139-146. [CrossRef]

55. Carreiras, J.M.B.; Quegan, S.; Le Toan, T.; Ho Tong Minh, D.; Saatchi, S.S.; Carvalhais, N.; Reichstein, M.; Scipal, K. Coverage of high biomass forests by the ESA BIOMASS mission under defense restrictions. Remote Sens. Environ. 2015, 196, 154-162. [CrossRef] 